\title{
ACCC's Authorisation Decisions: Interpretation of Public Benefit
}

\begin{abstract}
John Fallon
$\mathrm{T}$

The issue of the interpretation of the welfare standard that should be adopted in assessing the competitive effects and public benefits of mergers is an important one for ensuring competition laws are best placed to maximise the overall welfare of the community. Mergers are reviewed under Section 50 of the Australian Trade Practices Act which prohibits mergers that 'would have the effect, or be likely to have the effect, of substantially lessening competition in a market'. Although not fully tested in the courts, Section 50 of the Australian Trade Practices Act is generally considered to embody a consumer welfare standard rather than a total or overall welfare standard that would give prominence to overall economic efficiency. (Economic efficiencies refer to any improvements in the productivity of resources or their value to consumers through either better use of resources in a particular activity or a better allocation of resources in terms of the mix of factors of production in a particular activity or the mix and scale of output that is produced. In addition, there are both static and dynamic dimensions that characterise economic efficiencies. The concepts of productive, allocative and dynamic efficiency are often used to describe the various aspects of economic efficiency.) This is because in determining if a merger would substantially lessen competition in a market, Section 50 (3) imposes the specific requirement to determine 'the likelihood that significant and sustainably higher prices or profit margins would result'. In practice this means that in assessing mergers in accordance with Section 50, economic efficiencies which promote competition and benefit consumers (or users of a product or service) directly are relevant but not efficiencies which only benefit producers even where there is relatively small harm to consumers (Walker, 2000:386). Note also that since the Act came into force in 1974 there have only been four fully argued merger cases and none of these have considered efficiencies (Everett and Ross, 2002:31 and Williams and Woodbridge, 2001:6). In addition, all four of these cases were argued under the old 'dominance test' which has been replaced by the 'substantial lessening of competition test'.

The authorisation provisions in Part VII of the Act that relate to both mergers and other anti-competitive arrangements provide scope for the adoption of a total welfare standard where all efficiencies can be treated as public benefits. In the context of a two-step process the existence of two welfare standards with the one for authorisation of mergers being more comprehensive than the one for testing for a substantial lessening of competition may be reasonable. Although the welfare
\end{abstract}

Dr John Fallon is a Vice-President in the Canberra office of CRA International. The views in this paper are personal and not necessarily those of CRA International. 
standard adopted by the Australian Competition and Consumer Commission (ACCC) for authorisations is potentially more comprehensive than a consumer welfare standard, in practice there seems to be a tendency to give greater weight to efficiencies that directly benefit consumers than to efficiencies that directly benefit producers. Reflecting this tendency, Smith (2003:5) has argued that a consumer welfare standard is usually applied to authorisation decisions in Australia.

This paper focuses on the evidence and implications of such a tendency by the ACCC in its authorisation decisions. It first reviews standards that have emerged in Australia and internationally in the consideration of efficiency gains and their distributional impacts. It then reviews numerous authorisation decisions of the ACCC highlighting key aspects that support the proposition that the ACCC tends to give greater weight to effects on consumers than to effects on firms and some of the weaknesses in the ACCC's approach. It concludes with a discussion of the policy implications of this tendency and suggestions for improvement.

\section{Welfare Standards}

Based on Everett and Ross (2002:20-23) and Duhamel and Townley (2002:26-35), the welfare standards that have emerged in the context of assessing mergers fall into six categories as follows: Price standard; Consumer Surplus standard; Total Surplus standard; Hillsdown standard; Balancing Weights standard; and other Weighted Surplus standards.

\section{Figure 1: Welfare Impacts of a Merger}

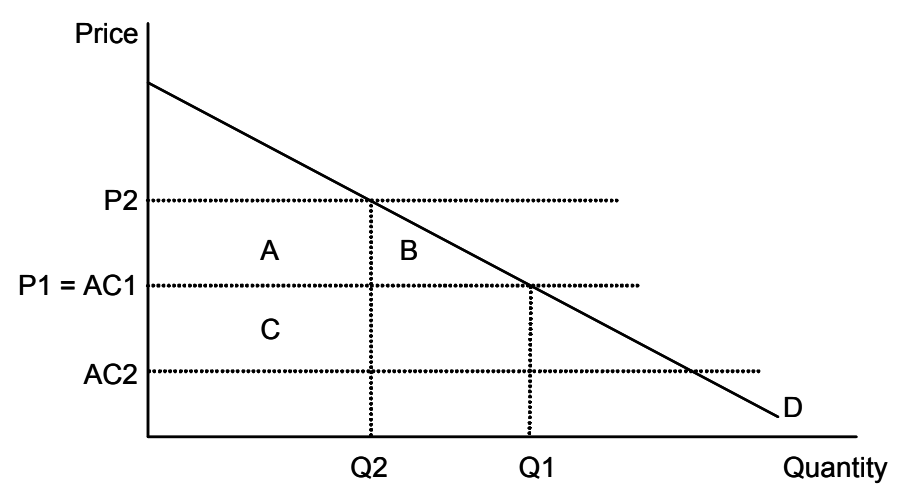

The standards can be understood by reference to Figure 1. In the pre-merger situation price is $\mathrm{P} 1$ equal to average cost $\mathrm{AC} 1$ and output is Q1. Following the merger price increases to $\mathrm{P} 2$ and output falls to $\mathrm{Q} 2$ as a result of the use of market power. However productive efficiency (for example, rationalisation) gains mean that average cost falls to AC2. The merger entails a deadweight (allocative efficiency) loss of B (as a result of the higher price and reduced output), a transfer of consumer surplus to producers of A (as a result of the higher price for output that is still purchased) and a producer surplus gain of $\mathrm{C}$ (as a result of productive 
efficiency gains). Note that the effects on consumer and producer surpluses net of transfers as depicted in Figure 1 are allocative efficiency losses and productive efficiency gains respectively.

\section{Price standard}

The price standard is simply that a merger leading to a price increase will not be approved. In terms of Figure 1, since the price rises, the merger would not be approved irrespective of the net efficiency effects. The standard is consistent with the actual Pareto improvement criterion in that at least one person is made better off with no person being made worse off. With this standard, efficiencies must be strong enough to lead to benefits to both producers and consumers. This standard is extreme in the sense that it effectively gives all the weight to consumers or a zero weight to producers if there is a price increase.

\section{Consumer surplus standard}

A variation on the price standard is the consumer surplus standard as defined by Everett and Ross (2002). It extends the price standard by allowing for other nonprice factors that impact on consumer surplus. Under this standard, if a merger leads to an increase in price but consumer surplus still rises (for example, because of improved quality or the value associated with new products or services) it would be approved. If consumer surplus does not increase, then the merger would not be approved irrespective of the gains in producer surplus. This is basically the same as the price standard in terms of the weight it gives to consumers, but it allows for other factors besides price effects.

\section{Total surplus standard}

The total surplus standard is simply that a merger that results in an increase in the sum of consumer and producer surplus would be approved. With this standard a pure transfer from consumers to producers would be treated neutrally. With reference to Figure 1, the merger would be approved if $\mathrm{C}>\mathrm{B}$. The total surplus standard is the standard total welfare approach that most economists adopt in analysing a merger where there is scope for productive efficiency gains (for example, cost savings through rationalisation) and enhanced market power. It is consistent with the potential Pareto improvement criterion in the sense that, assuming the marginal utility of income for different groups is the same, there are net gains and no one is worse off to the extent that hypothetical compensation could occur. This standard assumes that there is no need to make a distinction between a dollar gain to one group and a dollar loss to another group. Alternatively only efficiency effects need to be considered and distributional effects can be disregarded 


\section{Hillsdown standard}

For the Hillsdown standard a transfer from consumers to producers is treated as a net cost in the sense that the benefit to producers is not recognised. The producer surplus associated with efficiency gains counts but the producer surplus from the exploitation of market power does not.

The Hillsdown standard is based on a description by Justice Reed in the Canadian Hillsdown decision where she suggested that under some conditions the transfer of surplus from consumers to producers, associated with a post-merger price increase, should be viewed as a negative cost of the merger (Everett and Ross, 2002:22). Under the Hillsdown standard a merger would be approved, even if prices increased, provided the net efficiency gains were larger than any transfer from consumers to producers. In terms of Figure 1, the merger would only be approved if $\mathrm{C}>\mathrm{A}+\mathrm{B}$. Although this standard may have some popular appeal, there is no economic basis for it, and it represents an arbitrary compromise between the price standard and the total surplus standard.

\section{Balancing weights standard}

The balancing weights standard proposed by Duhamel and Townley (2002) entails calculation of distributional weights for different groups so that the net benefits of a merger would be exactly zero and asking whether such weights are reasonable. In terms of Figure 1, the balancing weight of $x$ (assuming $\$ 1$ to consumers has a weight of 1) would be found from the solution of $x(A+C)-(A+B)=0$. Note that from this relationship, $x$ is the ratio of losses to consumers relative to gains to producers and $1-x$ indicates the extent to which gains to producers would have to be discounted if the standard was just met or just failed. In considering whether the implied weight is reasonable, a value judgement is required as to whether producers should receive a weighting relative to consumers implied by the ratio $x$, that is, whether their gains should be reduced by a discount factor of $1-x$.

\section{Other weighted surplus standards}

Other weighted surplus standards assign some sort of 'social weight' to the various effects of a merger reflecting the importance the reviewing body gives to each group. Various approaches have been suggested by weights implicit in various public policy decisions (Boardman et al, 2001:456-472).

The most promising approach for taking account of distributional concerns is to try to determine a lower bound weight (that is, upper bound discount factor) based on the cost to higher income groups of implementing a social welfare transfer system. Under this approach an estimate could be made of the marginal cost of taxation needed to support a transfer to lower income groups. This is used to make an upper bound estimate of the cost that society considers is reasonable to provide an additional transfer to lower income groups. For example, suppose that the marginal cost of taxation implies an efficiency cost to the economy of $\$ 1.50$ to transfer an additional $\$ 1$ from higher to lower income groups. This can be used to 
determine the upper bound estimate of the extent to which gains to higher income groups should be discounted in order to transfer $\$ 1$ to lower income groups. In this case if the implicit 'balancing' weight that has been calculated is less than $1 / 1.5$ then the implication is that there is an alternative policy that would achieve the same 'broad' distributional objective as preventing the merger but at a lower cost to the economy and higher income groups. An objection could be raised that the individuals benefiting from or harmed by the merger would not necessarily correspond to those represented in this calculation, and in any case the scenario is hypothetical. However these same criticisms would apply to all public policy decisions wherever the hypothetical Kaldor-Hicks compensation principle was applied and rejection of consideration of policies based on hypothetical compensation would effectively lead to policy paralysis.

Note also that the setting of weights based on the tax system would not be sufficient to determine an optimal set of weights since the benefits of transfers and government expenditure on different groups of individuals would need to be incorporated. Alternatively the weights might also represent factors that represent the likelihood of the effects being sustained which appears to be the main justification of differential weights proposed by the ACCC.

\section{Qualifications and extensions}

It is important to recognise that the presentation of the above standards in terms of Figure 1 is from a highly simplified perspective where competition is assumed to diminish following a merger and static analysis is also appropriate. In Figure 1, the situation prior to a merger is assumed to be perfectly competitive and the merger leads to the realisation of both market power and some productive efficiency gains. However, the evaluation of whether market power is likely to be enhanced is more complex in the situation where prior to the merger the market is characterised by oligopolistic competition.

The basic welfare standards described above can still be applied in such circumstances. However, analysis of a merger's effects on competition and of its implications for price and efficiency outcomes becomes more complicated. In most cases there is a need to assess factors such as the nature of imperfect competition before and after a merger, the incentives for sustained efficiency gains given the expected impact on market structure and competitive rivalry, and the scope for different stakeholders to expend resources in securing some component of the efficiency gains (that is, the concept of socially wasteful rent seeking).

In relation to the competitive process, oligopolistic markets (where firms are aware of the interdependency of their decisions) can support a range of outcomes from highly competitive marginal cost pricing to a form of tacit collusion consistent with a monopoly outcome. Assessment of a merger's competitive effects therefore requires consideration of the nature of competition before and after the merger (see Ivaldi et al, 2003, for a thorough discussion). There is also a need to assess the extent to which efficiency gains are likely to be sustained given likely changes in the nature of competition or dissipated if competitive pressures 
are weakened. As will be explained below the ACCC has demonstrated concern about the dissipation of efficiency gains following a merger and such concerns seem to be the key rationale it offers to justify discounting of gains to producers.

\section{The ACCC Position}

The Trade Practices Act does not define what constitutes a 'public benefit' in relation to the statutory test for a public benefit. The only specific matters that the Act refers to are in Section 90(9) which specifies that a significant increase in exports or substitution of domestic products for imported goods must be treated as benefits as well as all relevant matters that relate to the international competitiveness of Australian industry.

Officer and Williams (1995:163-65) and Hanks and Williams (1987:165-67) perceived a longstanding difference between the ACCC and the Australian Competition Tribunal in their interpretations of public benefit. Fels and Grimwade (2003:202-205) also referred to a number of studies that consider that the ACCC favours a consumer welfare standard (where, in effect, benefits to consumers are valued over the benefits to producers) over a total welfare standard (where effectively benefits to producers and consumers are valued equally). However, they noted that the concern of the ACCC, at least in recent times, is not one based on redistribution of wealth from producers to consumers, but whether efficiency gains will be sustained over time or more likely to be dissipated through managerial slackness or rent seeking (pp. 201-02).

The key point is that the ACCC tends to discount benefits if they are not in a form of direct benefits to consumers. Thus efficiencies in the form of cost savings tend to be discounted by the ACCC if they are not substantially passed through to consumers in the form of lower prices or improved services. However, the discounting of such benefits is not based on a systematic and transparent process and the extent of implied discounting in decisions appears to vary depending on the extent of efficiencies and the extent to which pass through of cost savings to consumers are assessed to occur. In terms of the welfare standards described above, the ACCC is effectively adopting either a price or consumer welfare standard or applying weights to producers' gains that entail a substantial discount factor for uncertainty as to their sustainability. In a speech in 2002, Commissioner Jones suggested that it was possible for a merger to be authorised even where there are substantial anti-competitive consequences (Jones, 2002:20-22). However, as he noted, the cases he referred to where authorisation was granted, entailed either some pass through of efficiencies to consumers or improvements in international competitiveness or increased competition in other markets.

Examples of authorisations with these characteristics include the acquisition by Monier of the Wunderlich roof tile business (1983), the acquisition by Henderson's Federal Spring Works Pty Ltd of National Springs Pty Ltd (1987), the joint venture between Australian Mining and Smelting Limited and North Broken Hill Holdings Ltd (Pasminco Ltd 1988), the ACI Operations Pty Ltd acquisition of Smorgons (1991), the Davids acquisition of Composite Buyers 
(Trade Practices Commission, 1995), the agreement between Qantas Airways Limited and British Airways Pty Ltd to coordinate various aspects of their airline services (1995), the acquisition by Davids Limited of QIW Limited (ACCC, 1996a) and the joint venture for the exclusive marketing of sodium cyanide between Dupont (Australia) Limited and Ticor Limited (ACCC, 1996b).

In the 1999 Merger Guidelines (ACCC, 1999), there is a relatively broad interpretation of public benefit, although the ability to discount private benefits is noted, particularly where such benefits are not considered to be durable. This is demonstrated by the following excerpts from the 1999 Merger Guidelines:

6.42 The concept of a benefit to the public is not limited to benefit to consumers, a benefit to a private party which is a value to the community generally is a public benefit. ...

6.43 Furthermore when comparing the situation that is likely to prevail with and without the proposed merger, it is critical to consider the likely durability of the claimed public benefits. ...

Examples of the ACCC's tendency to discount benefits to producers that are not passed on to consumers and to give greater prominence to pro-competitive effects rather than pro-efficiency effects include the proposed joint venture between CSR Limited and Mackay Sugar Co-operative Association for sugar refining and sale in the domestic and export markets (1994), Wattyl (Australia) Limited's proposed acquisition of Taubmans Industries Ltd paint manufacturing and supply business (ACCC, 1996c), the proposed merger between Australian Pharmaceutical Industries Ltd and Sigma Company Ltd (ACCC, 2002), and the proposed alliance between Qantas and Air New Zealand (ACCC, 2003).

For example, in its Determination of the Qantas-Air New Zealand proposed alliance the ACCC (2003:para 13.65) said:

Finally it should again be noted that the cost saving benefits accrue to the Applicants and their shareholders. While the Commission is of the view that benefits to a particular group or segment of the Community may be regarded as benefits to the public, consideration needs to be given as to whether the community has an interest in that group being benefited and whether that benefit is at the expense of others - for, example, consumers through higher prices. The level of competition in a market will affect both the durability of the benefit and the likelihood and extent of that benefit being passed through to consumers. Where benefits are not passed on to consumers this may be symptomatic of a lack of competitive pressure that would otherwise cause such benefits to endure and be passed through. Such benefits are likely to be accorded a lower weight by the Commission.

This clearly indicates that in such circumstances a dollar gain to shareholders is not treated the same as a dollar loss to consumers by the ACCC. As noted, the ACCC's main justification for this does not appear to be one based on income distributional considerations but a concern that if cost efficiencies are not passed 
on, then this is evidence that it is most likely to be the case that such efficiencies will not be sustained because of a lack of competitive pressure. However there clearly seems to be confusion or inconsistency about this justification as reflected in the Australian Competition Tribunal's recent decision on the proposed QantasAir New Zealand alliance where it interpreted the ACCC's position as follows:

169 The Commission countered that the applicants were seeking to apply a total welfare or total surplus standard (the terms being inter-changeable) to determine net public benefit and submitted that this was not the correct approach to take. Both the Commission and the Gullivers Group submitted that, unless benefits were shared with consumers, it was inappropriate to characterise such benefits as 'public' benefits, except in exceptional circumstances, which circumstances they said were not present in this proceeding. They submitted that if these benefits were considered to be public benefits, when assessing the weight to be given to such benefits the Tribunal should regard them as deserving of little or no weight. By implication, the Commission and the Gullivers Group appeared to be advocating the use of the consumer welfare standard.

In its decision on the proposed airline alliance the Australian Competition Tribunal (2005) presented extensive reasoning on the interpretation of public benefit concluding that it preferred a total welfare standard but one which allowed different weights to be given to public benefits to the extent they are not shared among members of the community generally (para 190) or not likely to be sustained (para 189). It summarised its position as follows:

185 In our view, the objective and statutory language of the Act, as well as precedent, support the use of a 'form of' the total welfare standard because, as the passage cited from Re Howard Smith shows, whilst the Tribunal does not require that efficiencies generated by a merger or set of arrangements necessarily be passed on to consumers, it may be that, in some circumstances, gains that flow through only to a limited number of members in the community will carry less weight.

189 It follows that cost savings achieved by a firm in the course of providing goods or services to members of the public are a public benefit which can and should be taken into account for the purposes of s 90 of the Act, where they result in pass through which reduces prices to final consumers, or in other benefits, for example, by way of dividends to a range of shareholders or being returned to the firm for future investment. However, the weight that should be accorded to such cost savings may vary depending upon who takes advantage of them and the time period over which the benefits are received.

However, the Tribunal did not elaborate on how such weights would be determined or on the relevant time period when benefits accrue and how this would affect the weights. It is also important to recognise that the Tribunal's 
decision to authorise the alliance did not hinge on a different view of public benefits to the ACCC but rather a different assessment of the likely anticompetitive effects, particularly in the light of expansion of two other airlines on relevant routes since the ACCC's decision.

There is a perception that the Tribunal has a wider interpretation of public benefit than the ACCC and that its decision in the case brought by Qantas made reference to a wider test than precedents (see Crowe, 2005). This may have been true in the past but is not the case now.

Review of the Tribunal's reasoning in its airline decision and the ACCC's decision in that matter and in numerous other cases, and its Merger Guidelines suggests that both the Tribunal and ACCC now have a similar 'adjusted total welfare' standard. This standard is effectively a weighted surplus standard where public benefits can be weighted according to whether they accrue to particular groups and their likelihood of being sustained. Although the term 'total welfare' does not appear to have been used in the past, this form of a standard has been applied in previous determinations as has the concept of an 'adjusted total welfare' standard (see also Corones, 2005:307). What it is fair to say is that the ACCC may have moved to a broader standard or at least developed a more meaningful rationale for its 'adjusted total welfare standard' in recent years while the Tribunal in its latest decision provided more explanation for the standard to be applied in a public welfare test. However, they both effectively have the same standard now.

In terms of implementing the welfare standard, the ACCC's Merger Guidelines and various decisions provide an impression that adverse effects on consumers clearly are a detriment per se without any discounting in virtually all circumstances, whereas gains to shareholders may not be a public benefit per se and are likely to be given a lower weight if consumers suffer or there are no gains in international competitiveness or increased competition in other markets.

In particular, it seems that the ACCC may treat competition as an objective in itself, in the sense that any merger which clearly lessens competition substantially, even though it results in large efficiency gains, which may not be passed on to consumers, would be most likely to be rejected. To the extent that this is true it seems unreasonable in an assessment of public benefits since it provides no meaningful scope for a trade-off between efficiency gains and competition losses.

Although the ACCC might argue that the lack of pass through of efficiency gains may make such gains vulnerable to 'x-inefficiencies', the authorisation determinations do not report a transparent and economically meaningful approach to discounting for the extent to which gains to producers or shareholders are not passed on to consumers. Similar criticisms can be made about the ACCC's assertions that efficiency gains estimated by applicants are too large or efficiency losses too small without providing credible and transparent alternative estimates (see Ergas, 2003:8-9). Thus a key weakness with the approach of the ACCC to date is that there is no guidance on relevant weights so that the distributional/efficiency trade-off can be reasonably defined and evaluated and used as a basis to determine the likelihood of success of future proposed authorisations. 
Brunt (1994) has been influential in the ACCC's interpretation of public interest and in particular for the concept that benefits that are not passed on to consumers may not be durable because they are more likely to be dissipated through rent seeking or $\mathrm{x}$-inefficiencies as referred to in the ACCC's Merger Guidelines. She has recently summarised her thinking as follows (Brunt, 2003:83):

It is undeniable that 'the community as a whole' may be viewed as a collection of producers as well as a collection of consumers; it is undeniable that producers are just as good as consumers. What is advocated here as the public interest is not the sacrifice of one group to another but the placing of primary reliance upon an efficient and progressive process - if possible, a competitive process - which leads up to consumption. There is a sense in which in the long-run 'everybody is better off' if consumption becomes the end of production.

In response to Brunt it is undeniable as an economic principle that consumption (widely defined) as opposed to production is an ultimate objective in terms of maximising economic welfare. However, that does not necessarily mean that in evaluating mergers resulting in price increases, directly affected consumers should be given more weight than shareholders who benefit from efficiency gains as Brunt advocates. There is a need to take a broader view of economic welfare and in particular the perspective of the community as a whole. If efficiency gains are not passed on there can be income gains for the community as a whole that can support higher overall consumption including on a longer term basis. It also does not mean that competition should be given priority over economic efficiency, as the competitive process is a means to achieve economic efficiency but is not necessarily effective in achieving that objective in all circumstances.

Achievement of efficiency requires a wide view of the competitive process and efficient allocation of resources. In particular, there is a number of mechanisms reflecting competition for resources in the economy that ultimately benefit consumers. If for example a merger entails rationalisation so that certain production, storage or distribution functions are not required, then the assets and other resources associated with such functions become available for use elsewhere in the economy. Furthermore, such a reallocation of resources would normally be characterised by economists as a durable benefit for the economy as a whole.

There is also a need for a clearer understanding of the $\mathrm{x}$-inefficiency concept. The ACCC and Brunt appear to be concerned about the scope for x-inefficiency where rationalisation benefits are not passed on. It is helpful to consider the concept in more detail to highlight some weaknesses in its interpretation.

The x-inefficiency concept, originally developed by Liebenstein (1966), relates essentially to situations where the effort of employees and managers in a firm is less than is socially optimal (Liebenstein, 1998). According to Liebenstein, this arises because of non-maximising behaviour by employees and managers and the inability to implement a first-best monitoring and enforcement mechanism to ensure optimal effort is realised. The outcome is lower effort and 'an easier life' 
for employees and managers. Firms may anticipate the problem and adjust compensation and production techniques to try redress it but the outcome is a lower level of efficiency for the firm than in the absence of the problem.

It is also important to recognise that $\mathrm{x}$-inefficiency is not equivalent to economic inefficiency as part of the $\mathrm{x}$-inefficiency is simply a transfer from shareholders to factors of production. X-inefficiency can however entail some waste to the extent that resources are expended in attempting to secure and prevent transfers (often referred to as rent seeking). But some of these expenditures will be optimal to the extent that they are needed to secure an optimal level of effort in a situation where there are information problems (Stigler, 1976). An important implication that follows from Stigler's perspective is that in assessing the impact of a merger one needs to consider how the merger will impact on monitoring arrangements. That is, does the merger somehow lead to less effective performance monitoring arrangements? There is an extensive literature using the principal-agent framework that examines how competition might improve incentives for efficiency. However, generally the theoretical and empirical literature on the impact of competition on effort incentives is ambiguous.

Vickers (1995) provides a survey of concepts of competition highlighting the ambiguities in some of the theoretical literature including the application of the principal-agent methodology. He showed for example that 'competition-bycomparison' can improve effort incentives in a simple one-period model where explicit incentives can be created by performance contracts, the manager (agent) is risk averse, and the owner (principal) is risk neutral. With such assumptions, the ability to make comparisons reduces risk and facilitates explicit performance contracts that cause effort to be closer to the efficient level. However, with implicit incentives that arise naturally from market forces (for example, by affecting reputation and its effect on earnings prospects) the outcome of 'competition-by-comparison' on effort incentives is ambiguous because individual managers may be able to free ride on the efforts of others. Furthermore, Vickers shows that in a dynamic (more than one-period) setting, the 'ratchet effect', whereby good performance in the current period implies a higher target in the future weakens effort incentives. Studies by Meyer and Vickers (1997), Hart (2001) and Scharfstein (1988) using similar frameworks highlight similar ambiguities. Other studies highlight the countervailing mechanisms of the greater fear of liquidation in a more competitive market versus lower efforts induced by lower profits (Martin, 1993; and Schmidt, 1997).

The empirical literature is also equivocal. Interpretation of the empirical literature needs to recognise the difficulty in measuring competition by proxies such as market shares. One issue is that highly concentrated industries can still be characterised by intense competition. Another is that measures of market shares are themselves endogenous and affected by changes that influence both price and productivity performance and the intensity of competition. In addition many of the studies do not effectively isolate regulatory and other policy changes from competition measures. Although a review of the empirical literature is not provided here these issues are well highlighted by Symeonidis (2002). 
Finally the likelihood of $\mathrm{x}$-inefficiency effects worsening as a result of a merger needs to include an assessment of the relevance of capital market pressures in addressing any genuine cost inefficiencies that might arise as a result of $\mathrm{x}$ inefficiency effects. In this respect an interesting empirical study by Nickell, Nicolitsas and Dryden (1997) found evidence that financial market pressure and shareholder control can substitute for competition and that in particular the impact of competition on productivity performance is lower when firms are under financial pressure or have a dominant external shareholder.

The key point is that in relation to an assessment of $\mathrm{x}$-inefficiency, thorough and transparent analysis has not been evident in any of the ACCC's decisions reviewed in this paper.

\section{Implications for Policy}

In summary both the ACCC and the Tribunal advocate that the appropriate welfare standard for assessing public benefits is an 'adjusted total welfare standard'. This means that while the starting point is the standard total welfare concept that is well grounded in economic theory, the ACCC and the Tribunal consider it appropriate to adjust that standard depending on the distribution of the benefits and costs between consumers and firms and their employees and shareholders and the extent to which they perceive certain gains to be sustainable.

Although there may be a perception that this approach reflects income distributional concerns, the main justification offered by the ACCC is that efficiency gains are not likely to be sustained by firms unless they are passed on to consumers. The ACCC further contends that such gains will be dissipated in the form of $\mathrm{x}$-inefficiency and costly rent seeking effects. However, there remains some ambiguity in the positions of both the ACCC and the Tribunal about whether the dollar gains for firms and shareholders will be given the same weight as the same dollar costs for consumers when there is no sustainability issue and based perhaps on a legal interpretation of public benefit.

The standard total welfare concept in economics can take account of uncertainty and also incorporate income distributional concerns. However the incorporation of uncertainty requires a meaningful assessment of risk and the incorporation of distributional concerns requires setting of weights for different groups. The setting of such weights in turn entails value judgements about the optimal distributional impact. Thus, although there is scope in the standard framework to determine differential weights for effects on consumers and firms and their employees and shareholders, the problem remains that both the ACCC and the Tribunal have not clarified and established a consistent, transparent and economically sound framework for determining appropriate weights. Indeed they have provided very little information on how they approach these tasks.

Numerous decisions and the ACCC's Merger Guidelines suggest that it is unlikely to authorise a merger, regardless of the extent of any efficiency gains, if consumer prices increase and there are no improvements in competition in other markets or in international competitiveness. As noted, the main justification for 
this seems to be a perception that efficiency gains that are not passed on to consumers are less likely to be sustained than direct gains to consumers. However, there are grounds for suspicion that the risk of efficiency gains not being sustained is considered by the ACCC to be whatever is required to discount efficiency gains if they are not passed through to consumers and there are no improvements in competition in other markets or in international competitiveness. This is what is known in retailing as the 'butcher's thumb' approach.

In practice authorisation has played a limited role in respect of mergers, and together with the lack of transparency in the ACCC's decisions, where efficiency gains are discounted, this means that there is little clear precedent parties can draw upon in deciding whether to seek authorisation (see also Ergas, 2002). In addition it would seem that in order for a merger to pass the informal clearance process, there would be a need to demonstrate clearly that prices were not likely to rise or that enforceable undertakings were agreed to that effectively ensured that a consumer welfare standard was met. A consequent danger is that there are real risks that too many merger opportunities that would improve overall economic welfare are discouraged or precluded by the standards and the process.

Furthermore, in those situations where the sustainability of efficiency gains can be reasonably demonstrated, there is still the issue of whether a dollar gain to a shareholder should be treated the same as a dollar loss to a consumer. As noted, resolving such an issue requires a value judgement about optimal distributional impacts and there are considerable difficulties in determining appropriate weights from the perspective of society as a whole. However, it also raises the issue of ensuring sufficient and effectively designed policy instruments to address each major objective of the government and how to best use policy instruments to achieve specific policy objectives. There is a longstanding theorem in economics that the number of specific policy instruments should be at least equal to the number of specific policy objectives, otherwise conflicts emerge (Tinbergen, 1952). There is also a widespread acceptance amongst economists that in evaluating a public project a dollar should be treated as dollar irrespective of the incidence effects and that distributional concerns should be addressed through the tax and transfer system (Harberger, 1971; Parish, 1976; and Ng, 1984). There are some qualifications to these positions when there is uncertainty about the effectiveness of a policy instrument as this may mean that it is optimal to use more than one instrument to achieve a specific policy objective (Kelsey, 1988; and Ng, 1988). However, a reasonable case could be made that competition policy is not well designed to address income distributional goals, including when uncertainty of the effectiveness of policies is recognised, and that such goals would be more effectively addressed separately by the tax and transfer system.

From a public policy perspective it would be useful if the ACCC and the Tribunal were to make their deliberations about the extent of uncertainty of the sustainability of efficiency gains more meaningful from an economic perspective and more transparent. Similarly, it would be useful if they would clarify whether income distributional considerations should be part of the overall welfare standard that both the ACCC and the Tribunal should be required to consider. There is also 
a good case for legislative guidance to be provided on these issues. Both the ACCC and Tribunal can expect to continue to be pursued on these issues in academic, commercial and political fora until they are effectively resolved.

\section{References}

Australian Competition and Consumer Commission (1996a), 'Application for Authorisation by Davids Limited in Relation to the Proposed Acquisition of QIW Limited', A30174, 28 March).

Australian Competition and Consumer Commission (1996b), 'Application for Authorisation by DuPont (Australia) Ltd, Ticor Ltd, Howson Algraphy (Australasia) Pty Ltd and Ticor Chemical Company Pty Ltd', A90581 and A 90582, 8 May.

Australian Competition and Consumer Commission (1996c), Application for Authorisation by Wattyl (Australia) Pty Ltd, Courtaulds (Australia) Pty Ltd and Pinchin Johnson (Australia) Pty Ltd', A30175, 17 May.

Australian Competition and Consumer Commission (1997), 'Application for Authorisation by Bristile Holdings Limited', A70010, 3 November.

Australian Competition and Consumer Commission (1999), Merger Guidelines.

Australian Competition and Consumer Commission (2002), 'Application for Authorisation by Australian Pharmaceutical Industries Limited in Respect of a Proposed Merger with Sigma Company Limited', A30215, 11 September.

Australian Competition and Consumer Commission (2003), 'Application for Authorisation by Qantas Airways Limited of Ordinary Shares in Air New Zealand Limited and Cooperative Arrangements Between Qantas, Air New Zealand and Air Pacific', A30220, A30221, A30222, A90862, and A90863, 9 September.

ACI Operations Pty Ltd (1991), ATPR (Cth), ๆ50-108.

Australian Competition Tribunal (2005), Qantas Airways Limited [2004] AcompT 9, 16 May.

Boardman, A., D. Greenberg, A. Vining and D. Weimer (2001), Cost Benefit Analysis: Concepts and Practice, Prentice Hall.

Brunt, M. (1994), 'The Australian Antitrust Law After 20 years - A Stocktake', Review of Industrial Organisation 9(5):508.

Brunt, M. (2003), Economic Essays on Australian and New Zealand Competition Law, Kluwer Law International.

Canada (Director of Investigation and Research) v Hillsdown Holdings (Canada) Ltd. (1992), 41 C. P. R. (3d) in Everett and Ross (2002:22).

Corones, S. (2005), 'Restrictive Trade Practices: Tribunal Decision in Qantas: Assessing Anticompetitive Detriment and Public Benefit in Authorisation Proceedings', $A B L R$ 33:305-11.

Crowe, D. (2005), 'Beware, Graeme, There's a Watchdog Watching You', The Weekend Australian Financial Review, 6 August, p. 22. 
CSR Limited, Mackay Sugar Co-operative Association Limited, ED and F Man Australia Pty Ltd and Newco (1994), ATPR, $\mid 50-138$.

Duhamel, M. and P. Townley (2002), 'An Effective and Enforceable Alternative to the Consumer Surplus Standard', Competition Bureau, Industry Canada and Acadia University, mimeo.

Ergas, H. (2002), 'Review of Parts IV and VII of the Trade Practices Act 1974 (Cth): Note on Efficiencies in the Consideration of Mergers', Network Economics Consulting Group, mimeo.

Ergas, H. (2003), 'Quantifying Benefits in the Assessment of Authorisation Applications', Network Economics Consulting Group, mimeo.

Everett, A. and T. Ross (2002), 'The Treatment of Efficiencies in Merger Review: An International Comparison', University of British Columbia and Delta Economics Group Inc., mimeo.

Fels, A. and T. Grimwade (2003), 'Authorisation: Is it Still Relevant to Australian Competition Law?', Competition and Consumer Law Journal 11:187-214.

Hanks, F. and P. Williams (1987), 'The Treatment of Vertical Restraints Under the Australian Trade Practices Act', Australian Business Law Review 15:147-69.

Harberger, A.C. (1971), 'The Three Basic Postulates for Applied Welfare Economics: An Interpretative Essay', Journal of Economic Literature 9:785-97.

Hart, O. (2001), 'The Market Mechanism as an Incentive Scheme', Bell Journal of Economics 14:366-382.

Henderson's Federal Spring Works Pty Ltd (1987), ATPR (Cth.) ๆ50-054.

Howard Smith Industries Pty Ltd (1977), ATPR $\llbracket 40-023$, at 17,334.

Ivaldi, M., B. Julien, P. Rey, P. Seabright and J. Tirole (2003), 'The Economics of Unilateral Effects', Interim Report for DG Competition, European Commission.

Jones, R. (2002), 'The Rationale for Mergers Law', The Thirteenth Annual Workshop of the Competition and Policy Institute of New Zealand.

Kelsey, D. (1988), 'Policies to Achieve a Better Distribution of Income: Or is a Dollar a Dollar?’, Oxford Economic Papers 40:577-583.

Liebenstein, H. (1966), 'Allocative Efficiency vs 'X-efficiency', American Economic Review 56:392-415, June.

Liebenstein, H. (1998), 'X-efficiency Theory', 934-935 in J. Eatwell, M. Milgate and P. Newman (eds), The New Palgrave: A Dictionary of Economics, The Macmillan Press Limited, London.

Martin, S. (1993), 'Endogenous Firm Efficiency in a Cournot Principal-Agent Model', Journal of Economic Theory 59:445-450.

Meyer, M. and J. Vickers (1997), 'Performance comparisons and dynamic incentives', Journal of Political Economy 105(31):547-581.

Monier Limited (1983), ATPR (Cth) \50-062. 
Ng, Y. (1984), 'Quasi-Pareto Social Improvements', American Economic Review 74:10331050 .

Ng, Y. (1988), 'Is a Dollar a Dollar? A Response', Oxford Economic Papers 40(3):584586.

Nickell, S., D. Nicolitsas and N. Dryden (1997), 'What Makes Firms Perform Well?, European Economic Review 41:783-96.

Officer, R. and P. Williams (1995), 'The Public Benefit Test in an Authorisation Decision', 157-166 in M. Richardson and P. Williams (eds), The Law and the Market, The Federation Press, Sydney.

Parish, R. (1976), 'The Scope of Benefit-Cost Analysis', Economic Record 52:302-314.

Pasminco Ltd (1988), ATPR (Cth) $\mid 50-082$.

Qantas Airways Limited and British Airways Plc (1995) ATPR (Cth) ๆ50-184.

Scharfstein, D. (1988), 'Product Market Competition and Managerial Slack', Rand Journal of Economics 19:147-155.

Schmidt, K. (1997), 'Managerial Incentives and Product Market Competition', Review of Economic Studies 64:191-213.

Smith, R. (2003), 'Authorisation and the Trade Practices Act: More About Public Benefit', Competition and Consumer Law Journal 11:1-22.

Stigler, G. (1976), 'The Xistence of X-Efficiency', American Economic Review 66(1):21316.

Symeonidis, G. (2002), The Effects of Competition, MIT Press, Boston.

Tinbergen, J. (1952), On the Theory of Economic Policy, North-Holland, Amsterdam.

Trade Practices Commission (1975), First Annual Report (year ended 30 June) para. 3.83.

Trade Practices Commission (1978), Fourth Annual Report (year ended 30 June) para. 2.6.

Trade Practices Commission (1995), Application for Authorisation Lodged by Davids Limited in Relation to the Proposed Acquisition of Composite Buyers Limited, A30165, 29 May.

Vickers, J. (1995), 'Concepts of Competition', Oxford Economic Papers, 47:1-23.

Walker, J. (2000), 'Mergers', Chapter 7 in Butterworths Australian Competition Law.

Williams, P. and G. Woodbridge (2001), 'Antitrust Merger Policy: Lessons from the Australian Experience', National Bureau of Economic Research Twelfth Annual East Asian Seminar on Economics, Hong Kong University of Science and Technology.

I would like to acknowledge the helpful comments of Greg Cutbush, Henry Ergas and two anonymous referees and research by Jason Soon on some of the citations on $x$-inefficiencies and incentive schemes. 